\title{
TRAÇOS DE UMA HISTÓRIA: UM PRIMEIRO OLHAR DA INFLUÊNCIA DE JOHANN MÜLLER REGIOMONTANUS NAS OBRAS DO MATEMÁTICO PORTUGUÊS PEDRO NUNES
}

\author{
Ana Carolina Costa Pereira \\ Universidade Esadual do Ceará - UECE - Brasil \\ Bernadete Barbosa Morey \\ Universidade Federal do Rio Grande do Norte - UFRN - Brasil
}

(aceito para publicação em outubro de 2018)

\begin{abstract}
Resumo
Os séculos XV e XVI foram marcados pelo movimento do Renascimento, um período em que houve um reavivamento do interesse pela arte e pela ciência antiga. A Matemática floresceu principalmente nas cidades mercantis em desenvolvimento, sob a influência do comércio, da navegação, da astronomia e da agrimensura. Nessa época, Johann Müller Regiomontanus (1436-1476) teve um importante papel para a independência da Trigonometria em relação à Astronomia e Pedro Nunes (1502-1578) foi o principal responsável pela renovação dos estudos de astronomia teórica na Europa Latina nesse século. O presente estudo se propõe a buscar traços da influência de Regiomontanus nas obras do matemático português Pedro Nunes. Cientista multifacetado e filósofo, Pedro Nunes não deixou em suas obras apenas assuntos ligados à Astronomia aplicada e à Náutica. A Matemática estava presente, principalmente ligada ao estudo da Geometria e da Álgebra. Nesse estudo, percebemos uma forte ligação do cosmógrafo com Regiomontanus nas obras: Tratado da Sphera, De crepusculis, Erratis Orontii Finaei Regii Mathematicarvm Lvtetiae Professoris, De arte adque ratione navigandi e o Libro de Algebra en Arithmetica y Geometria. Desse modo, investigações envolvendo a relação do desenvolvimento matemático do século XVI em detrimento da produção científica e a influência ocasionada por suas obras, podem transparecer o momento da produção de conhecimento de uma determinada época.
\end{abstract}

Palavras-Chave: História da Matemática Portuguesa. Obras de Pedro Nunes. Johann Müller Regiomontanus. 


\title{
[TRACES OF A HISTORY: A FIRST LOOK AT THE INFLUENCE OF JOHANN MÜLLER REGIOMONTANUS ON THE WORKS OF THE PORTUGUESE MATHEMATICIAN PEDRO NUNES]
}

\begin{abstract}
The fifteenth and sixteenth centuries were marked by the beginning of the Renaissance, a period in which there was a revival of interest in art and ancient science. Mathematics flourished mainly in the developing mercantile cities, under the influence of trade, navigation, astronomy and surveying. In those centuries, Johann Müller Regiomontanus (1436-1476) played an important role in the independence of the field of Trigonometry and Pedro Nunes (1502-1578) was the main responsible for the renewal of theoretical astronomy studies in Latin America in that century. The present study is to look for traces of the influence of Regiomontanus on the works of the Portuguese mathematician Pedro Nunes. A multifaceted scientist and philosopher Pedro Nunes did not leave in his works only subjects related to Applied Astronomy and Nautical. Mathematics was present, mainly linked to the study of Geometry and Algebra. In this study, we notice a strong connection of the cosmographer with Regiomontanus in the works: Tratado da Sphera, De crepusculis, Erratis Orontii Finaei Regii Mathematicarvm Lvtetiae Professoris, De arte adque ratione navigandi and Libro de Algebra en Arithmetica y Geometria. Thus, investigations involving the relationship of mathematical development of the sixteenth century to the detriment of scientific production and the influence occasioned by works and their creators, may reveal the moment of the production of knowledge of a given epoch.
\end{abstract}

Keywords: History of Portuguese Mathematics. Works by Pedro Nunes. Johann Müller Regiomontanus.

\section{Introdução}

Na busca de fragmentos que possam ter motivado o nascimento de um enunciado e/ou prova de um teorema, novos conceitos, propriedades, ou mesmo um novo ramo da matemática podem tanto interessar ao historiador como ao matemático. $\mathrm{O}$ olhar que é dado a um certo conceito ao longo da história, por exemplo, pode ser diferente dependendo do foco e da formação do pesquisador. Segundo Grabiner (1975), enquanto o matemático vê o passado como parte do presente e o historiador vê o presente carregado com relíquias arqueológicas do passado. Eles, o historiador e o matemático, veem os fatos do presente como tendo várias raízes no passado, concebidos por longos e complexos processos, muito desses providos de situações históricas particulares.

Nesse ponto, as considerações propostas aqui, não têm o olhar de um historiador, nem tão pouco de um matemático, pois consideramos que ambas são áreas de conhecimentos distintos, com objetos bem definidos. Nossa visão está relacionada na formação do professor de matemática ou mesmo no campo da Educação Matemática, cuja 
busca por uma interface entre história, ensino e aprendizagem matemática permeiam interesses dos atuais pesquisadores.

Nesse sentido, a busca por evidencias históricas oriundas de fatos deixados ao longo dos tempos, seja ela por meio de fontes primárias (textos, imagens, documentos, entre outros) ou mesmo por fontes secundárias (trabalhos de outros autores) podem questionar, complementar, ou aperfeiçoar uma formação, visto que as "narrativas históricas não são neutras e são influenciadas por diferentes fatores ligados não só a formação, mas também à concepção de ciência de quem escreve a história" (SAITO, 2016, p. 257).

Dentre os diversos temas vinculados a História da Matemática, o século XV é considerado por muitos pesquisadores como o período do reavivamento do interesse pela arte e pela ciência antiga, ou seja, o Renascimento. Outro fato é a invenção da imprensa por Johannes Gutenberg, em 1456, que ajudou bastante na propagação de tratados que antes eram destinados a uma pequena parcela da população.

No que se refere às ciências exatas, a impressão livros ocasionava grandes dificuldades para os impressores dessa época, devido principalmente à escrita de "equações matemáticas, diagramas e tábuas astronômicas que apresentavam problemas de arte tipográfica muitas vezes de grande complexidade" (LEITÃO, 2002b, p. 63). Além dos problemas de impressão, publicar uma obra era extremamente cara, e muitas delas precisavam de financiamento, já que o público comprador era bastante reduzido.

Dentre os cientistas que contribuíram para o desenvolvimento da Matemática e da Astronomia no século XV encontramos Johann Müller Regiomontanus (1436 - 1476), um personagem de grande importância, pois " [...] construiu uma fundamentação uniforme e uma ordenação sistemática do conhecimento trigonométrico e fez observações para melhorar os cálculos das tábuas trigonométricas" (ZELLER, 1944, p. 19, tradução nossa).

Regiomontanus é autor de uma das obras mais importantes sobre trigonometria, De Triangulis Omnimodis Libri Quinque (Cinco Livros sobre Todos os Tipos de Triângulos). Escrito por volta de 1464 e publicado postumamente, em 1533. O tratado consiste na primeira exposição europeia sistemática de Trigonometria Plana e Esférica, uma tentativa importante de tratamento da Trigonometria de modo independente da Astronomia. Nessa época, a ciência náutica já havia florescido, gerando questões envolvendo a área da Trigonometria Esférica e suas propriedades geométricas, temas centrais para o estudo da navegação teórica e da astronomia.

Portugal era pátria de especialistas em navegações, de descobridores de novas terras e rotas, e dos criadores da célebre Estação Naval de Sagres. Produziu também um dos mais conhecidos matemáticos a ter notável projeção internacional, o cosmógrafo Pedro Nunes (1502 - 1578). Autor de diversas obras que retratam estudos sobre Álgebra, Geometria, Trigonometria Esférica, Astronomia náutica, entre outros, o cosmógrafo português, “(...) comprazia-se em salientar as raízes antigas de concepções modernas, em abonar com a autoridade dos gregos a sua opinião e em pôr a nu o erro de contemporâneos relativamente às suas próprias explicações". Leitão (2002a, p.31)

Deste modo, o intuito desse estudo é buscar traços de uma história que revele a influência das leituras feitas por Pedro Nunes das obras de Regiomontanus em trabalhos que foram publicados e chegam aos dias de hoje, em especial, o Tratado da Sphera, o De 
crepusculis, o Erratis Orontii Finaei Regii Mathematicarvm Lvtetiae Professoris, a De arte adque ratione navigandi e o Libro de Algebra en Arithmetica y Geometria.

\section{Descrição dos documentos do estudo}

O estudo proposto está baseado na metodologia da pesquisa documental que segundo Lakatos e Marconi (2010, p. 174), nela “(...) a fonte de coleta de dados está restrita a documentos, escritos ou não, constituindo o que se denomina de fontes primárias. Estas podem ser feitas no momento em que o fato ou fenômeno ocorre, ou depois".

Em trabalhos voltados para a Educação Matemática, as fontes primárias são textos históricos extraídos de documentos matemáticos originais, como por exemplo, artefatos históricos, documentos, manuscritos, obras originais, traduções, entre outros. Para essa pesquisa utilizamos uma fonte primária, a coleção das obras raras de Pedro Nunes publicado pela Academia de Ciências de Lisboa e financiada pela Fundação Calouste Gulbenkian tendo como coordenador científico o professor doutor Henrique Sousa Leitão.

A coleção de Obras de Pedro Nunes, conta com seis volumes os quais nos trazem o original, a tradução em português ${ }^{1}$ e comentários de cada tratado:

- Volume I: Tratado da Sphera; Astronomici introductorii de spaera epitome, 2014.

- Volume II: De Crepusculis, 2003.

- Volume III: De erratis Orontii Finaei, 2005.

- Volume IV: De arte atque ratione nauigandi, 2008.

- Volume V: Theoricas Planetarum Georgii Purbachii Annotationes, 2011.

- Volume VI: Libro de algebra en arithmetica y geometria, 2010.

Para esse trabalho, não utilizamos o volume V, Theoricas Planetarum Georgii Purbachii Annotationes, por se tratar de uma tradução de Pedro Nunes da obra de Georg Peuerbach (1423 - 1461).

Como forma de organizar nossos passos, fizemos, inicialmente, uma leitura longitudinal da tradução para o português das obras de Pedro Nunes, selecionando textos que o autor se reporta a Regiomontanus e suas obras (quadro 1). Um fato que nos ajudou nessa tarefa foi o "índice dos nomes citados" exposto no final dos livros após os comentários do coordenador científico do projeto. Nele contém as páginas em que Pedro Nunes cita Regiomontanus em seu texto original e na tradução.

\footnotetext{
${ }^{1}$ Ressaltamos que Pedro Nunes escreveu a maioria de suas obras em latim. A única publicada em português é o Tratado da Sphera de 1537.
} 
Traços de uma história: um primeiro olhar da influência de Johann Müller Regiomontanus...

Quadro 1 - Referências às obras de Regiomontanus por Pedro Nunes.

\begin{tabular}{|l|c|}
\hline \multicolumn{1}{|c|}{ OBRAS } & CITAÇÕES $^{\mathbf{2}}$ \\
\hline Tratado da Sphera; Astronomici introductorii de spaera epitome & 4 \\
\hline De Crepusculis & - \\
\hline De erratis Orontii Finaei & 3 \\
\hline Theoricas Planetarum Georgii Purbachii Annotationes & 6 \\
\hline Libro de algebra en arithmetica y geometria & 6 \\
\hline
\end{tabular}

Fonte: Elaborado pelas autoras.

Após essa primeira análise, observamos cada trecho selecionado, tentando identificar qual a obra que Pedro Nunes utilizou de Regiomontanus, relacionando as proposições e a matemática produzida na época. Nosso intuito é apresentar uma breve análise, pois para cada volume, é necessária uma dedicação maior, com leitura, releitura e a internalização de cada momento da história.

\section{Johann Müller Regiomontanus x Pedro Nunes: dois renascentistas com uma visão moderna de mundo}

Regiomontanus, cujo nome de nascimento é Johannes Müller von Königsberg, nasceu no dia 6 de junho de 1436, na pequena cidade de Königsberg, uma província de Francônia, na antiga Prússia Oriental. Pouco se sabe sobre sua infância, pois seus registros foram perdidos em sua cidade natal, num incêndio, em 1640.

Obteve sua formação inicial em casa e em 1447 e aos onze anos foi enviado para a Alemanha, onde iniciou seus estudos em dialética, na Universidade de Leipzig. Em 15 de abril de 1450, Regiomontanus se matriculou na Universidade de Viena, na Áustria, motivado pelo ensino da Matemática, da Astronomia e da Cosmologia. Em Viena, ele foi aluno Georg Peuerbach, amigo de estudos e pesquisas, realizando, conjuntamente, excelentes trabalhos, dentre eles o Epítome do Almagesto.

Regiomontanus foi professor da Faculdade das Artes da Universidade de Viena e da Universidade de Pressburg, na Hungria. Dentre suas obras mais famosas estão o De Triangulis Omnimodis Libri Quinque, escrito entre 1642-1463 e publicado em 1533; Tabulae directionum et profectionum, de 1467; Tabulae primimobilis de 1468, entre outros $^{3}$. Ele morreu prematuramente os 40 anos de idade.

Dentre suas obras, o De Triangulis Omnimodis Libri Quinque (Cinco livros sobre todos os tipos de triângulos) é considerado uma das mais importantes. Tal obra constitui-se no resumo de toda Trigonometria estudada na Europa até o século XV, ou seja, Regiomontanus buscou compilar todo o conhecimento de Trigonometria como um suporte à Astronomia nesse tratado. Isso fica evidente na apresentação do tratado em que ele

\footnotetext{
${ }^{2}$ As citações utilizadas para a construção do quadro foram retiradas das obras originais.

${ }^{3}$ Maiores detalhes sobre a vida e obra de Johannes Müller Regiomontanus ver Pereira (2010).
} 
ressalta: “[...] vocês, que desejam estudar grandes e maravilhosas coisas, que desejam saber sobre o movimento das estrelas, precisam ler estes teoremas sobre triângulos. Sabendo estas ideias abrirão a porta a tudo de Astronomia e para certos problemas geométricos" (HUGHES, 1967, p. 5).

De Triangulis possui duas edições. A primeira edição publicada em 1533, por John Petreus, em Nuremberg na Alemanha, para John Schöner. Segundo Pereira e Morey (2017, p. 82) essa edição "além de englobar os cinco livros, continha uma extensão com a obra $D e$ quadratura circuli, de Nicolau de Cusa, conjuntamente com a contestação de Regiomontanus".

A segunda edição ${ }^{4}$, editada por Daniel Santbech, foi publicada em 1561 por Hans Petri e por Petter Perna, em Basiléia na Suíça. Nessa, incluía mais onze páginas que continha algumas tabelas de senos, entretanto ele faz referência à primeira edição da obra.

O tratado De Triangulis está delineado em cinco livros, sendo que os dois primeiros tratam da Trigonometria Plana, contendo 57 páginas e os três últimos, a Trigonometria Esférica, com 74 páginas. No total encontramos 23 definições, 7 axiomas e 195 teoremas. Segundo Pereira e Morey (2017, p. 87):

"o tratado apresentado nos remete a conceitos, a definições e a teoremas importantes na História da Trigonometria Moderna. A nomenclatura utilizada por Regiomontanus é bastante análoga à de Ptolomeu, principalmente quando exibe a divisão da circunferência, dividindo o diâmetro do círculo em 120 partes e a circunferência em 360 partes iguais."

Outro tratado de Regiomontanus é o Tabulae directionum et profectionum, escrito na sua passagem pela Hungria e publicada em 1490, após sua morte, por Erhard Ratdolt (1442-1528,) em Augsburg. Nas 43 páginas iniciais ele traz trinta e um problemas astronômicos e nas 272 páginas seguintes diversas tabelas, dentre elas a do seno recto e da tabula fecunda, isto é, uma tábua de tangentes com raio igual a $100.000\left(\operatorname{tg} 45^{\circ}=100.000\right)$. Ressaltamos que no início dos problemas, ele se referiu a uma tabela de senos com o seno $90^{\circ}$ igual a 60.000 , entretanto, no problema 10 , ele utilizou o seno de $90^{\circ}$ igual a 100.000 , informando que seria mais útil. Pedro Nunes, também se refere a ela, como abordaremos posteriormente.

Outro trabalho de Regiomontanus é o Tradelist $t^{5}$, publicado em 1474, que consiste em uma única folha anunciando uma lista de obras importantes que ele pretendia publicar. Ao todo ele propõe publicar 29 obras não de sua autoria, sendo nove delas novas traduções. Obras de Ptolomeu, Euclides, Theon de Alexandria e Arquimedes estavam entre as enumeradas, muitas eram novas traduções, comentários e tratados do próprio

\footnotetext{
${ }^{4}$ Essa edição pode ser encontrada no observatório da Universidade de Viena, na coleção de obras raras (Disponível em: http://www.univie.ac.at/hwastro/. Acesso em: 10/092015). Outra fonte que pode ser utilizada é Hughes (1967), no qual encontra-se o original em latim e a tradução em inglês.

${ }^{5}$ Para visualizar o Tradelist (1474) de Regiomontanus veja Verlag (1972, p. 533).
} 
Regiomontanus. Além disso, tinha os atlas, 22 de fabricação própria, e os instrumentos, entre os quais relógios de sol portáteis. Era um empreendimento grandioso, infelizmente interrompido por sua morte prematura.

Regiomontanus ainda escreveu o tratado Scripta clarissimi mathematici, em 1469, publicado postumamente em 1544, na qual ele dá detalhes de vários de seus instrumentos, tais como Torqueto, Astrolábio Armilar e regula ptolemaei; Tabulae primi mobilis ( 1468); Efemérides (1474), entre outros.

O cosmógrafo e matemático lusitano Pedro Nunes viveu de 1502 a 1578, ou seja, em pleno Renascimento e tanto o saber quanto o fizeram parte da sua vida acadêmica. Nunes "foi, sobretudo, um criador de teorias náuticas aplicadas por outros e experimentadas no mar-oceano (o seu grande laboratório)" (VENTURA, 1985, p. 22).

Leitão (2003), um dos pesquisadores da ciência noniana, ressalta que "não existe ainda um estudo biográfico suficientemente desenvolvido que congregue os muitos elementos já apurados hoje em dia e que circulam em publicações dispersas" (LEITÃO, 2003, p. 45). O que sabemos sobre Pedro Nunes se resume nos documentos da corte portuguesa, passagens que foram escritas em suas obras publicadas e declarações de dois netos aos providos de julgamentos na inquisição portuguesa: Matias Pereira na inquisição de Coimbra (1623 a 1631) e Pedro Nunes Pereira na inquisição de Lisboa (1632 a 1632).

Pedro Nunes nasceu em Alcácer de Sal, em 1502, onde fez seus primeiros estudos de letramento (ler e contar). Não temos indícios do lugar onde ele fez os estudos primário ou secundário, nem dos fatores que o levaram ao interesse pela ciência.

Seus estudos universitários foram iniciados por volta de 1517 na Universidade de Salamanca, aos 15 anos e entre 1526 e 1527 tornou-se bacharel em Medicina pela Universidade de Lisboa. Segundo Almeida (2011, p. 18), Pedro Nunes:

"Terá iniciado estudos universitários por volta de 1517 frequentando a Universidade de Salamanca como aluno livre, a partir de 1521. Foi também nessa cidade que casou, no ano de 1523, com D. Guiomar Áreas (Aires) e deste casamento nasceram dois rapazes (Apolónio e Pedro) e quatro raparigas (Briolanja, Francisca, Isabel e Guiomar)."

O matemático português teve vários cargos, entretanto, foi o de cosmógrafo do reino lhe trouxe mais prestígio, em 1529, evidenciando seus estudos em astronomia. Lecionou Filosofia Moral (1529), Lógica (1530) e Metafísica (1531, 1532) na Universidade de Lisboa. Ainda em 1531, foi professor dos príncipes D. Luís e D. Henrique convidado por D. João III, rei de Portugal.

Treze anos depois, em 1544, foi convidado para "ler a cadeira de matemática na Universidade de Coimbra, que em 1537 fora transferida de Lisboa para aquela cidade" (COSTA, 1938, p. 17) e, em 1547, foi nomeado cosmógrafo-mor do reino, cargo provavelmente criado exclusivamente para ele.

Pedro Nunes publicou uma vasta coleção de traduções com anotações e comentários e trabalhos originais em diversas áreas: cosmografia, física, cosmologia, geometria, álgebra, entre outros. 
$\mathrm{Na}$ área de cosmografia, Pedro Nunes publicou três obras: Tratado da Sphera, 1537 (único livro publicado em Português), Astronomici introductorii de Spaera Epitome, sem data (entre 1537 e 1542); e o Petri Nonii Salaciensis Opera, quae complectuntur, primum, duos libros (1566).

No Tratado da Sphera ele traz três traduções comentadas e expandidas: Tractatus de Sphaera de Johannes de Sacrobosco, a Theoricae novae planetarum de Georg Purbach e a Geographia de Claudius Ptolemaeus, além de divulgar, como anexo, duas de suas obras sobre cosmografia: Tratado sobre certas dúvidas de Navegação e Tratado em defensam da carta de marear, e Tábuas do movimento do Sol e sua inclinação. O Astronomici introductorii de Spaera Epitome contém um resumo em latim de 12 páginas da obra Tratado da Sphera. E na obra Petri Nonii Salaciensis Opera, de 1566, Pedro Nunes apresenta a tradução em latim de alguns livros publicados no Tratado da Sphera. Mais tarde o autor expande, corrige e reedita o Petri Nonii Salaciensis Opera com um novo nome: De arte adque ratione navigandi, publicado em 1573.

Outra obra que versa sobre cosmografia, entretanto com um refinamento matemático, é o De crepusculis, de 1542. Nesse tratado original ele apresenta teorias sobre a astronomia esférica, que são indispensáveis para esse campo da ciência. Segundo Costa (1938, p. 42) "seu fim principal é o estudo da duração do dia e da noite, transformação de coordenadas astronômicas e outros problemas derivados dos movimentos dos astros", ou seja, a duração dos crepúsculos era o problema fundamental nessa obra. Costa (1938, p. 42) ainda ressalta que "neste trabalho Pedro Nunes mostra todo o valor do seu prodigioso gênio matemático. É ele considerado pelos modernos especialistas como a mais bela e mais original de suas obras".

Pedro Nunes ainda publica tratados de matemática pura. Na obra de dezenove capítulos De Erratis Orontii Finaei, Regii Mathematicarum Lutetiae Professoris de 1546 o cosmógrafo lusitano refuta os erros de Oronce Finé (1494 - 1555), Professor do Collège de France e aborda geometria pura; no Libro de Algebra en Arithmetica y Geometria, de 1567, ocupa-se da Álgebra e da Geometria aplicada. Ele também confeccionou um instrumento de sombras exposto no Opera quae complectuntur primum duos libros, o qual servia para encontrar a variação da agulha e o Nónio descrito na obra De Crepusculis liber unus.

Algumas das obras creditadas a Pedro Nunes estão perdidas. A referência a elas é feita pelo próprio autor no final do tratado De Crepusculis (NUNES, 2003, p. 260):

"Em breve, como esperamos, sairão a público outros opúsculos nossos, designadamente Do astrolábio, tratado demonstrativo; Dos triângulos esferais; Do planisfério geométrico; Da Proporção ao V de Euclides; Do traçado das pomas para a arte de navegar, e alguns outros que actualmente preparamos."

Outro indício de obra perdida pode ser encontrado no Tratado da Esfera (1537), em que Pedro Nunes comenta no final da sua última anotação no texto de Sacrobosco sobre uma possível obra intitulada Geometria dos Triângulos Esféricos: "Posto que eu toda via escreui a Geometria dos triangulos Spheraes largamente antes que de Alemanha nos mandassem a Espenha os Liuros de Geber e Monteregio que na mesma materia falam: $e$ 
despoys de lidos nam rompi o que tinha escripto" (NUNES, 2014, p. 45). Esse trecho nos evidencia o motivo pelo qual Pedro Nunes, não tivesse publicado a Geometria dos Triângulos Esféricos, pois provavelmente, após a publicação, em 1533, do tratado de Regiomontanus, De Triangulis Omnimodis Libri Quinque, julgou desnecessário uma vez que estava exposto de modo exímio e completo. Comprovando mais uma vez a leitura dos tratados de Regiomontanus.

Leitão (2002b) relata ainda que outras indicações implícitas e explicitas podem ser vistas no decorrer das obras publicadas por Pedro Nunes. O autor ainda traz uma lista de obras perdidas que foram compiladas por estudiosos das questões nonianas:

"De ortu et occasu signorum [Sobre o nascimento e ocaso dos signos] Geometria dos Triangulos spheraes;

De astrolábio opus demonstratiuum $[$ Do astrolábio, tratado demonstrativo]

Do planisphaerio geométrico [Do planisfério geométrico]

De proportione in quintum Euclidis [Da proporção ao $V$ de Euclides]

De globo delineado ad nauigandi artem [Do traçado das pomas para a arte de navegar]

Tradução, muito possivelmente comentada, do De Architectura, de Vitruvio. (LEITÃO, 2002b, 52)

Percebemos que uma dessas obras perdidas está relacionada diretamente com o livro do Regiomontanus, De Triangulis, a Geometria dos Triangulos spheraes. Razões para a não publicação serão discutidas posteriormente.

Regiomontanus e Pedro Nunes não se encontraram, pois, nem ao menos foram contemporâneos. No entanto, o conhecimento desenvolvido nesse período, devido principalmente à invenção da impressa, se propagava com maior rapidez e chegava a ter um alcance geográfico maior, ainda que, devido ao alto custo, essa transmissão de conhecimentos estivesse ainda restrita a poucos, muito longe da maioria da população.

Traços de leituras das obras de Regiomontanus podem ser encontrados nos escritos de Pedro Nunes, e essa influência pode ser devida à grande propagação dos tratados de Regiomontanus pela Europa. Um exemplo disso é o De Triangulis que é um marco no século XVI e atuou como suporte para estudos posteriores de matemáticos e astrônomos, tais como o polonês Nicolaus Copérnico (1473-1543) e o austríaco Georg Joachim von Lauchen Rheticus (1514 - 1574).

\section{Vestígios da influência de Regiomontanus nas obras de Pedro Nunes}

É sabido que Pedro Nunes leu algumas obras póstumas de Regiomontanus. Isso pode ser comprovado pelas várias passagens escritas que se referem aos trabalhos de Regiomontanus. Tais evidências podem ser encontradas em livros que fizeram parte da Biblioteca de Pedro Nunes, como o Tabulae directionum et profectionum (figura 1) escrito em 1467. Segundo Leitão (2002a, p. 33): 
“(...) esses livros apresentam marca de posse de Pedro Nunes e alguns deles exibem ainda extensas anotações marginais, quase de certeza pela mão do matemático português. (...) São obras 'de trabalho', livros usados no estudo ou como elementos de referência para a prática de um astrônomo-matemático."

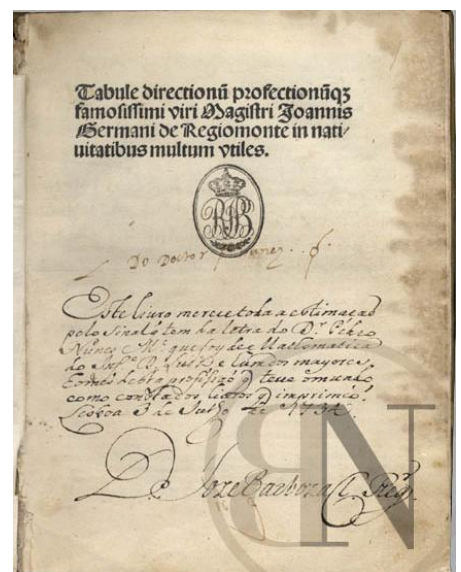

Figura 1 - Obra Tabulae directionum et profectionum, com a marca de posse de Pedro Nunes

Fonte: Reservados da Biblioteca Nacional portuguesa

No que se refere às obras publicadas por Pedro Nunes, algumas delas citam trechos dos tratados de Regiomontanus, que, na sua maioria, estão ligados ao estudo da geometria plana, esférica e alguns vestígios da álgebra.

Na sua primeira obra publicada, Tratado da Esfera (1537), Pedro Nunes faz quatro menções ${ }^{6}$. Dois comentários mencionam o livro quatro do De Triangulis, e uma que Pedro Nunes nomeia Regiomontanus como imitador dos trabalhos do árabe Jabir ibn Hayyan (c.721 - c.815), mais conhecido pelo seu nome latino, Geber:

"E quem esta figura com sua demostração contemplar: achara escusada toda a mais geometria de linhas curuas: e as proposições de Gebre de que tanto se vaãgroriou: e todos os liuros de Monteregio seu imitador: pera alcançar muitas cousas que Ptolomeu no segundo liuro do Almagesto per tantos rodeos demostra." (NUNES, 2014, p. 40-41)

\footnotetext{
${ }^{6}$ Uma delas já mencionada anteriormente sobre as obras perdidas de Pedro Nunes.
} 
No texto da obra De Crepvsculis, Pedro Nunes não cita Regiomontanus. Entretanto, dá indícios de leitura e utilização de suas obras. Um exemplo disso é o lema que fala do seno verso ou seno reverso, já quem no Tratado da Esfera (1537) ele utilizou o seno reto: "Sinus recti et uersi quoque similium arcuum eandem habent rationem et circulorum semidiametri" "7 (NUNES, 2003, p. 29). No ano da publicação do De Crepvscvlis Pedro Nunes já conhecia, sem dúvida as duas funções, mediante Regiomontanus, Geber, e Pedro Piano.

Ressaltamos que o seno reto não deve ser confundido com o seno de um ângulo reto. Reto é usado somente para enfatizar que o seno a que se refere não é o seno reverso ( 1 - cosseno) ou, geometricamente, aquela parte do raio que fica entre o seno de um ângulo e seu arco).

O seno, na época de Regiomontanus, difere ligeiramente da definição da função seno de hoje. O seno, como usado em sua obra, é uma perpendicular traçada de uma extremidade de um arco de um círculo para o diâmetro que foi traçado pela outra extremidade do arco. O seno reverso ou seno verso é a parte do diâmetro entre o pé daquela perpendicular ou o seno e o arco. O seno do complemento do arco é o seno da diferença entre o arco e um quadrante; consequentemente, se o arco é menor que $90^{\circ}$, o complemento do arco é $90^{\circ}$ menos os graus do arco, mas, se o arco é maior que $90^{\circ}$, o complemento é levado a ser os graus do arco menos $90^{\circ}$.

No tratado De Erratis Orontii Finaei Regii Mathematicarvm Lvtetiae Professoris, de 1546, Pedro Nunes, encontramos três menções a Regiomontanus. A primeira delas está logo no início, indicando que o livro contém "Praecipuarum tabularum directionum Joannis de Regiomonte demonstrativo, et usus" (NUNES, 2005, p. 4) ${ }^{8}$.

No capítulo XV, Refutação 12." "De como Orôncio errou crassamente na investigação das latitudes dos lugares, devido à ignorância dos primeiros rudimentos de Astronomia", Pedro Nunes, ao descrever o lugar aparente da Lua, diz que "Rursum per distantiam ipsius lunae a duabus stellis cognitis, quemadmodum in septimo libro epitomae Ioannis de monte Regio, uisus etiam locus cognosceretur” (NUNES, 2005, p. 83) ${ }^{9}$. A Epítome do Almagesto de Ptolomeu, é uma tradução com comentários e esclarecimentos. Ela foi iniciada por Peuerbach, e completada por Regiomontanus. Sua necessidade se fazia presente, pois ele deveria facilitar a compreensão da Astronomia contida no Almagesto de Ptolomeu, obra fundamental da Astronomia antiga. O Almagesto continha muitos atalhos incompreensíveis, que deveriam ser esclarecidos pelo Epítome.

A terceira menção feita por Pedro Nunes a Regiomontanus se encontra no Capítulo XVIII, refutação 15 . $^{\text {. }}$ Aqui o cosmógrafo diz que Orôncio cometeu um erro ao descrever o relógio noturno; diz também que Orôncio alega ter usados os problemas $2^{\circ}$., $4^{\circ}$. e $6^{\circ}$. da Tábuas de Direcções de João Regiomontano e que irá mostrar o erro cometido utilizando-

\footnotetext{
7 "Os senos rectos e versos equivalentes têm a mesma razão que os semidiâmetros dos círculos"7 (NUNES, 2003 , p. 166).

8 “A demonstração e uso das principais tábuas de direção, de João Regiomontanus" (NUNES, 2005, p. 129).

9 "Esse lugar também poderia ser conhecido pela distância da Lua a duas estrelas conhecidas, como indica João de Monte Régio no liv. VII do seu Epítome” (NUNES, 2005, p. 207).
} 
se dos mesmos problemas usados por Orôncio. (NUNES, 2005, p. 223) ${ }^{10}$. Neste mesmo capítulo Pedro Nunes fala da tábua fecuanda (NUNES, 2005, p. 231). A "tábua fecunda" (figura 2) é uma das tabelas que estão incluídas na Tabulae directionum et profectionum, isto é, ela é uma tábua de tangentes com $\operatorname{tg} 45^{\circ}=100.000$, ou seja, o raio é $\mathrm{R}=$ 100.000 .

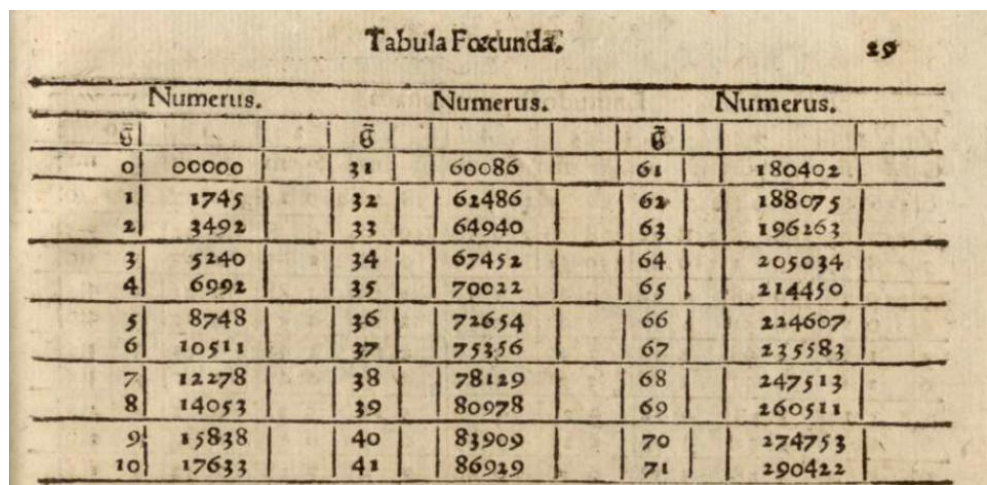

Figura 2 - Extrato da Tabula Fecunda.

Fonte: Regiomontanus (1559, p. 29)

Já na obra De arte adque ratione navigandi de 1573, encontramos 18 menções a obras de Regiomontanus, principalmente a Epítome do Almagesto (1462) e da Tabulae primi mobilis ( 1468). A primeira referência ao Epítome, Pedro Nunes faz no terceiro livro se referindo ao cálculo por dias de meses do equinócio de outubro que se deu em 24 de setembro: "Caeterum si calculum sequaris Georgii Purbachii et Ioannis de Monteregio, tertio libro Epito" 11 (NUNES, 2008, p. 72)

A Tabulae directionum et profectionum também é citada. Em vários momentos Pedro Nunes se refere aos seus problemas e faz indicação do seu uso:

"Caeterum constat eosdem autores stellarum fixarum motus a sectione uernali computare, longitudinis ângulo sphaerici trianguli constituto ad polum eclipticae octauae sphaerae, quemadmodum tabulae directionum Ioannis de Monteregio subiiciunt". ${ }^{12}$ (NUNES, 2008, p. 74)

\footnotetext{
10 "e que descobriu isto pela doutrina dos problemas $2 .^{\circ}, 4 .^{\circ}$ e $6 .^{\circ}$ da Tábuas de Direcções de João Regiomontano" (NUNES, 2005, p. 223)

11 "Mas, se seguirdes o cálculo de Jorge Purbáquio e de João de Monterégio, no 3. " livro do Epitome" (NUNES, 2008, p. 327)

12 "Mas é sabido que estes autores calculam os movimentos das estrelas fixas a partir da intersecção vernal, depois de determinado o ângulo de longitude do triângulo esférico no pólo da eclíptica da oitava esfera, tal como indica as Tábuas de direcções de João de Monterégio" (NUNES, 2008, p. 328-329)
} 
Outra obra citada por Pedro Nunes é a Tabulae primi mobilis "Idem demonstrauit Vernerus in libro de motu octauae sphaerae, et annotatum fuit a Ioanne de Monteregio problemate 62"13 (NUNES, 2008, p. 77). Supunha-se Regiomontanus fez Tabulae primi mobilis para simplificar os cálculos que eram muito laboriosos e demorados, uma vez que os logaritmos não tinham sido ainda inventados. Por exemplo, a tábua poderia ser usada para calcular o seno desconhecido de um ângulo que era igual ao produto de dois senos de ângulos conhecidos:

$$
\operatorname{sen}\left(90^{\circ}-a\right)=\operatorname{sen}\left(90^{\circ}-b\right) \operatorname{sen}\left(90^{\circ}-c\right), \mathrm{e} \operatorname{sen}\left(90^{\circ}-\alpha\right)=\operatorname{sen}\left(90^{\circ}-a\right) \operatorname{sen} \beta .
$$

Para finalizar, no Libro de Algebra en Arithmetica y Geometria, Pedro Nunes faz poucas referências as obras de Regiomontanus, apenas seis. Uma delas está na proposição $44^{14}$ do capítulo 7 intitulado, "A Prática da Álgebra nos casos dos exemplos da Geometria, e primeiramente dos quadrados", Pedro Nunes diz: "Si la proporcion de dos lados desiguales del triangulo fuere conoscida, y las partes de la base adonde cae la perpendicular fuere conoscidas, seran los dos lados conoscidos, y será la perpendicular conoscida y la area" (NUNES, 2010, p. 360). Na demonstração Pedro Nunes cita a proposição $12^{15}$ e $14^{16}$ do livro II De Triangulis de Regiomontanus.

O interessante é que Pedro Nunes no final da demonstração da proposição 52: " $\mathrm{Si}$ la differencia que ay entre las partes de la base diuisa por la perpendicular fuere conoscida, y la diferencia de los dos lados fuere tãbien conoscida, y la perpendicular, la base, y sus partes, y los seram conoscidos". (NUNES, 2010, p. 366) ${ }^{17}$ faz menção a proposição $23^{18}$ do livro II De Triangulis de Regiomontanus que ele resolve utilizando Álgebra ${ }^{19}$.

Apesar da obra De Triangulis ser direcionada à área de Geometria e Trigonometria, há momentos que, em algumas demonstrações, Regiomontanus se utiliza da Aritmética e da Álgebra. Algumas proposições e o manuseio da Álgebra se adequam para o autor à medida que existem teoremas que não podem se provados, no momento, por meios geométricos.

\footnotetext{
13 “O mesmo demonstrou Verner, no livro Do movimento da oitava esfera, e foi anotado por João de Monterégio, no problema 62 da Tábua do primeiro móvel” (NUNES, 2008, p. 332).

${ }_{14}$ "Se as proporções dos lados desiguais do triângulo forem conhecidas, e a parte da base onde cai a perpendicular forem fornecidas, serão os dos alunos conhecidos, e será a perpendicular conhecida e a área" (NUNES, 2010, p. 360 - tradução nossa).

15 "Se a perpendicular é dada e a base e a razão dos lados são conhecidas, cada lado pode ser encontrado". (PEREIRA, 2010, p. 173)

16 "Se cada um de dois segmentos desiguais é dado, e se a soma dos lados é também dada, cada lado pode ser determinado". (PEREIRA, 2010, p. 175)

17 "Se a diferença que há entre as partes da base dividida pela perpendicular for conhecida, a diferença dos dois lados também for conhecida a perpendicular, a base e suas partes serão conhecidas ". (NUNES, 2010, p. 366 tradução nossa)

18 "Se a diferença de dois lados é determinada e a diferença dos dois segmentos é conhecida juntamente com sua própria perpendicular, todos os lados podem ser encontrados”. (PEREIRA, 2010, p. 183)

${ }^{19}$ Para ver a demonstração da proposição 23 ver Pereira (2010, p. 183).
} 
Regiomontanus aplica assim exemplos, utilizando Álgebra para ilustrar a aplicação. É importante ressaltar que não há evidências sobre uma obra escrita por Regiomontanus que envolva essa parte da Matemática.

\section{Considerações finais}

Pedro Nunes conhecia certamente a produção científica de Regiomontanus, por quem manteve uma evidente admiração, apesar de, em alguns passos, lhe contestar as opiniões. Obras como Epítome do Almagesto de Ptolomeu, Tabulae directionum et profectionum e De Triangulis Omnimodis Libri Quinque tiveram grande importância no cenário europeu no século XV e provavelmente fizeram parte do acervo de matemático português.

Muitas referências a Regiomontanus podem ser encontradas em tratados de Pedro Nunes como apresentado nesse estudo. Entretanto, é importante, num próximo passo, fazer uma análise minuciosa do conteúdo matemático de cada obra, utilizando a vertente historiográfica atualizada no movimento lógico-histórico (SAITO; DIAS, 2013).

Além disso, um parecer mais crítico ainda pode ser realizado com as obras de Pedro Nunes, ou mesmo autores que as utilizaram posteriormente como Copérnico (14731543) e Rheticus (1514 - 1574), corrigindo tabelas ou mesmo aperfeiçoando a Trigonometria de Regiomontanus.

Dessa forma, o presente estudo é apenas um início de vários desdobramentos da influência do matemático da Francônia, Johann Müller Regiomontanus, para a ciência a partir do século XV no sentido de fazer um mapeamento de sua importância para a área de Trigonometria.

\section{Referências}

ALMEIDA, Bruno José M. G. Pereira de. A influência da Obra de Pedro Nunes na Náutica dos séculos XVI e XVII: Um estudo de transmissão de conhecimento. 2011. 595 f. Tese (Doutorado) - Curso de História e Filosofia das Ciências, Universidade de Lisboa, Lisboa, 2011.

COSTA, Abel Fontoura da. Pedro Nunes: (1502 - 1578). Lisboa: Agencia Geral do Ultramar, 1938.

GRABINER, Judith V.. The mathematician, the historian, and the history of mathematics. Historia Mathematica, Amsterdam, v. 1, n. 4, p.439-447, 1975.

LAKATOS, Marina de Andrade; MARCONI, Eva Maria. Fundamentos de metodologia científica. São Paulo: Editora Atlas, 2010.

LEITÃO, Henrique, «Sobre as "obras perdidas" de Pedro Nunes», in: Henrique Leitão, Lígia Azevedo Martins (Coords.), Pedro Nunes, 1502-1578: Novas terras, novos mares e o que mays he: novo ceo e novas estrelas. Lisboa: Biblioteca Nacional, 2002b, p. 45-66. LEITÃO, Henrique. Novos resultados sobre a importância das obras de Pedro Nunes. In: Memórias da academia das ciências de Lisboa (Classe de Ciências). Lisboa, 53, v. 01, 2006/2007, p. 317-340. 
LEITÃO, Henrique. Para uma biografia de Pedro Nunes: o surgimento de um matemático, 1502-1542. Cadernos de Estudos Sefarditas, Lisboa, v. 3, p.45-82, 2003.

LEITÃO, Henrique. Pedro Nunes, leitor de textos antigos e modernos. In: Aires A. Nascimento (Coord.), Pedro Nunes e Damião de Góis - Dois Rostos do Humanismo Português. Actas de Colóquio no V Centenário do Nascimento. Lisboa: Guimarães Editores, 2002a, p. 31-58.

NUNES, Pedro. Obras, vol. I, (Tratado da Sphera; Astronomici introductorii de spaera epitome). Lisboa: Academia das Ciências de Lisboa / Fundação Calouste Gulbenkian, $2^{\mathrm{a}}$ edição, 2014.

NUNES, Pedro. Obras, vol. II, (De crepusculis). Lisboa: Academia das Ciências de Lisboa / Fundação Calouste Gulbenkian, 2003.

NUNES, Pedro. Obras, vol. III, (De erratis Orontii Finaei). Lisboa: Academia das Ciências de Lisboa / Fundação Calouste Gulbenkian, 2005.

NUNES, Pedro. Obras, vol. IV, (De arte atque ratione nauigandi). Lisboa: Academia das Ciências de Lisboa / Fundação Calouste Gulbenkian, 2008.

NUNES, Pedro. Obras, vol. V, (Theoricas Planetarum Georgii Purbachii Annotationes). Lisboa: Academia das Ciências de Lisboa / Fundação Calouste Gulbenkian, 2011.

NUNES, Pedro. Obras, vol. VI, (Libro de algebra en arithmetica y geometria). Lisboa: Academia das Ciências de Lisboa / Fundação Calouste Gulbenkian, 2010.

PEREIRA, Ana Carolina Costa. A Obra "De Triangulis Omnimodis Libri Quinque" de Johann Müller Regiomontanus (1436 - 1476): uma contribuição para o desenvolvimento da Trigonometria. 2010. 329 f. Tese (Doutorado) - Curso de Educação, Universidade Federal do Rio Grande do Norte, Natal, 2010.

PEREIRA, Ana Carolina Costa; MOREY, Bernadete Barbosa. Revisitando a lei dos cossenos para triângulos esféricos: um aporte histórico do século XV. História da Ciência e Ensino: Construindo Interfaces, São Paulo, v. 15, p.81-95, 2017.

SAITO, Fumikazu. História e Ensino de Matemática: construindo interfaces. In: SALAZAR, Jesús Flores; GUERRA, Francisco Ugarte (Org.). Investigaciones en Educación Matemática. 1ed. Perú: Fondo Editorial PUCP, 2016, p. 253-291.

SAITO, Fumikazu; DIAS, Marisa da Silva. Interface entre história da matemática e ensino: Uma atividade desenvolvida com base num documento do século XVI. Ciência \& Educação, São Paulo, v. 19, n. 1, p.89-111, 2013.

VAN BRUMMELEN, Glen. The mathematics of the heavens and the earth: The Early History of Trigonometry. New Jersey: Princeton University, 2009.

VENTURA, Manuel Sousa. Vida e obra de Pedro Nunes. Lisboa: Oficinas Gráficas da Minerva do Comércio, 1985. 165 p.

VERLAG, Otto Zeller (Comp.). Joannis Regiomontani Opera Collectanea. OsnabrÜck: Proff \& Co. Kg Bad Honnef A. Rhein, 1972. Felix Schmeidler (Editor).

ZELLER, Mary Claudia. The development of trigonometry from Regiomontanus to Pitiscus. Ann Arbor: University of Michigan doctoral dissertation, 1944.

ZINNER, Ernst. Regiomontanus: His Life and Work. Amsterdam/New York/Oxford/Tokyo: North-Holland, 1990. Tradução de: Ezra Brown. 


\section{Ana Carolina Costa Pereira}

Departamento de Matemática - UECE - campus do Itaperi/Fortaleza - Brasil

E-mail: carolina.pereira@uece.br

\section{Bernadete Barbosa Morey}

Departamento de Matemática -UFRN - campus de Natal - Brasil

E-mail: bernadetemorey@gmail.com 